\title{
Wear and Osteolysis of Highly Crosslinked Polyethylene at 10 to 14 Years: The Effect of Femoral Head Size
}

\author{
Paul F. Lachiewicz MD, Elizabeth S. Soileau BSN, John M. Martell MD
}

Published online: 23 April 2015

(C) The Association of Bone and Joint Surgeons (B) 2015

\begin{abstract}
Background Highly crosslinked polyethylene (XLPE) was introduced to decrease periprosthetic osteolysis related to polyethylene wear, a major reason for revision of total hip arthroplasty. However, there are few reports of wear and osteolysis at 10 years postoperatively.

Questions/purposes (1) What are the linear and volumetric wear rates of XLPE at 10 to 14 years? (2) What is the relationship among linear wear, volumetric wear, and femoral head size? (3) What proportion of hips developed osteolysis and was there a relationship between osteolysis and femoral head size or polyethylene wear?
\end{abstract}

The institutions of the authors (PFL, JMM) received a grant from Zimmer, Warsaw, IN, USA.

All ICMJE Conflict of Interest Forms for authors and Clinical Orthopaedics and Related Research ${ }^{\circledR}$ editors and board members are on file with the publication and can be viewed on request.

Clinical Orthopaedics and Related Research ${ }^{\circledR}$ neither advocates nor endorses the use of any treatment, drug, or device. Readers are encouraged to always seek additional information, including FDAapproval status, of any drug or device prior to clinical use.

Each author certifies that his or her institution approved the human protocol for this investigation, that all investigations were conducted in conformity with ethical principles of research, and that informed consent for participation in the study was obtained.

This work was performed at Chapel Hill Orthopedics Surgery \& Sports Medicine, Chapel Hill, NC, USA, and the University of Chicago Medical Center, Chicago, IL, USA.

P. F. Lachiewicz $(\bowtie)$, E. S. Soileau

Chapel Hill Orthopedics Surgery \& Sports Medicine, 101

Conner Drive, Suite 200, Chapel Hill, NC 27514, USA

e-mail: paul.lachiewicz@gmail.com

J. M. Martell

Department of Orthopaedic Surgery and Rehabilitation

Medicine, University of Chicago Medical Center, Chicago, IL, USA
Methods We evaluated a previously reported cohort of 84 hips (72 patients) with one design of an uncemented acetabular component and one electron beam 10-kGy irradiated and remelted XLPE at a mean followup of 11 years (range, 10-14 years). The choice of femoral head size was based on several factors, including the outer diameter size of the acetabular component implanted, the perceived risk of dislocation (including the history of alcohol abuse and patient age), and liner availability from the manufacturer. The femoral head sizes used were $26 \mathrm{~mm}$ in 10 hips (12\%), $28 \mathrm{~mm}$ in 31 hips (37\%), $32 \mathrm{~mm}$ in 31 hips (37\%), $36 \mathrm{~mm}$ in eight hips (10\%), and $40 \mathrm{~mm}$ in four hips (5\%). Measurements of linear and volumetric wear were performed in one experienced laboratory by the Martell method and analyzed using the first-to-last method. Standard radiographs, with additional Judet views, were used to detect periprosthetic osteolysis. Statistical analysis of wear and osteolysis compared with head size was performed.

Results For the entire cohort, the median linear wear rate as $0.024 \mathrm{~mm} /$ year $(95 \%$ confidence interval [CI], 0.0160.030 ) and the median volumetric wear rate was $12.19 \mathrm{~mm}^{3} /$ year $(95 \% \mathrm{CI}, 6.6-15.7)$. With the numbers available, we found no association between femoral head size and linear wear rate. However, larger femoral heads were associated with more volumetric wear; 36/40-mm femoral heads had higher volumetric wear (median 26.1; 95\% CI, 11.3-47.1) than did 26-mm heads (median 3.1; 95\% CI, 0.7-12.3), 28-mm heads (median 12.3; 95\% CI, 3.0-19.3), and 32-mm heads (median 12.9; 95\% CI, 6.6$16.8 ; \mathrm{p}=0.02$ ). Small osteolytic lesions were noted in 12 hips (14\%), but with the numbers available, there was no association with head size or volumetric wear rates.

Conclusions This uncemented acetabular component and this particular XLPE had low rates of linear and volumetric wear. Small osteolytic lesions were noted at 10 to 14 years 
but were not related to femoral head size or linear or volumetric wear rates. We recommend additional longerterm clinical followup studies and perhaps alternative imaging studies of patients with XLPE and osteolysis.

Level of Evidence Level III, therapeutic study.

\section{Introduction}

The long-term success of THA has been limited by periprosthetic osteolysis related to particulate polyethylene wear debris, and this is considered an important cause of aseptic loosening and late implant failure [9, 26]. Fixation of an uncemented, titanium fiber-metal modular acetabular component with screw fixation has been highly successful. One study found a $100 \%$ survival rate of fixation of this component at 15 years, but there was a high incidence of pelvic osteolysis when it was used with conventional polyethylene [18]. Highly crosslinked polyethylene (XLPE) was developed to decrease polyethylene wear and hopefully decrease or eliminate osteolysis. This material has been studied in vitro and has decreased wear rates compared with conventional polyethylene in hip simulator studies [10]. Clinical studies of XLPE in small series of patients have confirmed these laboratory studies with a $45 \%$ to $99 \%$ reduction in wear compared with conventional polyethylene at 3 to 5 years $[3,5,7,9,22]$.

Numerous methods are used to fabricate XLPE acetabular liners, including differences in crosslinking radiation doses (50-100 kGy), radiation techniques (gamma or electron beam), thermal treatments to remove free radicals (melted or annealed), and terminal sterilization packaging method (gas plasma, ethylene oxide, or gamma irradiation). These differences influence the mechanical properties, oxidation levels, and likely also the long-term wear properties of the material. Thus, the numerous implanted XLPE acetabular liners are not all equivalent, and their performances both in vitro and in long-term clinical studies are likely to be different. Biomechanical studies of electron beam 10-kGy remelted XLPE (Longevity; Zimmer, Warsaw, IN, USA) acetabular liners have shown low in vitro linear wear even when paired with larger (greater than $32 \mathrm{~mm}$ ) femoral head sizes [10]. The clinical studies of the wear of this XLPE with large femoral heads reported low linear wear rates at 3 to 7 years $[2-4$, 7]. Our previous study using the titanium fiber-metal acetabular component and this XLPE showed low linear wear and no osteolysis at 5 to 8 years followup, but there was more volumetric wear in those hips with 36- and 40-mm femoral heads [15]. There are few studies of XLPE with 10-year followup time, but these are limited by small numbers of patients and different wear measurement techniques $[1,8,11,13,25]$. To our knowledge, there are no studies using the measurement method described by Martell of the linear and volumetric wear of electron beam $10-\mathrm{kGY}$ remelted polyethylene and the presence of osteolysis at a minimum followup of 10 years.

Thus, we asked the following questions: (1) What are the linear and volumetric wear rates of XLPE at 10 to 14 years? (2) What is the relationship among linear wear, volumetric wear, and femoral head size? (3) What proportion of hips developed osteolysis and was there a relationship between osteolysis and femoral head size and volumetric polyethylene wear?

\section{Materials and Methods}

This was a retrospective study of 130 patients (146 hips) who had a primary THA by the senior author (PFL) between December 1999 and April 1, 2003. All patients had a modular titanium fiber-metal uncemented acetabular component fixed with screws (Trilogy Multihole; Zimmer). The acetabular liner was an electron beam 10-kGy irradiated remelted highly crosslinked polyethylene (Longevity; Zimmer). In the previous study [15], we reported the results of 92 patients with 105 hips who had a minimum 5-year followup (mean, 6 years; range, 5-8 years). Before a minimum 10-year followup, 23 patients ( $25 \mathrm{hips}$ ) of the initial cohort of 130 patients (146 hips) had died, and 34 patients (35 hips) did not return for followup. Two patients who died (two hips) had reoperations before 5-year followup (one for recurrent dislocation, one for two periprosthetic femur fracture fixation procedures). Two patients with three hips had radiographs inadequate for wear measurement, leaving 72 patients $(56 \%)$ with 84 hips $(58 \%)$ with complete clinical and radiographic examination at a minimum 10-year followup (mean, 11 years; range, 10-14 years). Of these, 43 patients were male (52 hips) and 29 were female (32 hips). The mean patient age was 61 years (range, 37-81 years). Forty-eight patients were younger than 60 years. The mean body mass index was $29 \mathrm{~kg} / \mathrm{m}^{2}$ (range, $19-46 \mathrm{~kg} / \mathrm{m}^{2}$ ). The preoperative diagnosis was osteoarthritis in 54 hips, osteonecrosis in 16 hips, rheumatoid arthritis in three hips, and other diagnoses (traumatic arthritis, pediatric hip disease, or others) in 11 hips.

All procedures were performed through the posterior approach by one surgeon (PFL) who was not involved in the development of the implants. The acetabular component was a modular titanium fiber-metal uncemented component fixed with screws [18]. The choice of femoral component fixation was based on several factors, including diaphyseal bone quality, femoral anatomy, and other patient demographic factors. There were 52 uncemented 
titanium femoral components and 32 cemented chromecobalt alloy femoral components implanted.

The femoral head was a cobalt-chrome alloy in all hips and the choice of femoral head size was based on several factors, including the outer diameter size of the acetabular component implanted [14], the risk of dislocation (including history of alcohol abuse and patient age), as previously determined in studies from the senior author [16, 17, 24], and liner availability from the manufacturer. The femoral head sizes used were $26 \mathrm{~mm}$ in 10 hips (12\%), $28 \mathrm{~mm}$ in 31 hips (37\%), $32 \mathrm{~mm}$ in 31 hips (37\%), $36 \mathrm{~mm}$ in eight hips (10\%), and $40 \mathrm{~mm}$ in four hips (5\%) Because there were only four hips with a 40-mm head, these hips were combined with the hips with a 36-mm head as a single group for wear and osteolysis analysis. As a result of differences in availability of the liner and indications for 36- and 40-mm head sizes, the mean age of those patients with $36-/ 40$-mm heads ( 75 years; range, 66-81 years) was greater than those with 26-, $28-$, and 32-mm heads (58 years; range, 37-81 years; $\mathrm{p}<0.001)$.

Clinical evaluations were performed at 6 months, 1 year, and yearly or biennially thereafter by on experienced clinical research nurse (ESS) using the modified Harris hip score [12]. The patients were also asked to complete the Lower Extremity Activity Score (LEAS) at the most recent examination.

Standard supine AP pelvis and frog-lateral radiographs were performed in one outpatient orthopaedic clinic by trained technologists. The radiographs were performed at 6 to 8 weeks postoperatively (baseline radiograph), at 1 year postoperatively, and, if possible, at yearly or biannual visits. All 72 patients (84 hips) were recalled for the most recent or minimum 10-year followup, and at this visit, two additional $45^{\circ}$ Judet views were performed to detect osteolytic lesions of the pelvis. However, there were no preoperative or 6- to 8 -week postoperative Judet views. The radiographs were evaluated for radiolucent lines and component migration by one observer (ESS) [6, 23]. The acetabular component abduction angle, anteversion angle, and polyethylene wear were measured by one observer (JMM) on the AP pelvis radiograph using a previously described Martell method [20-22]. The followup radiographs were digitized and evaluated blindly at another medical center for acetabular component position and linear and volumetric wear by one experienced researcher (JMM) who was not involved in the care of these patients. Osteolysis on the AP pelvis or Judet view radiographs was defined as a localized area of bone loss, at least $1 \mathrm{~cm}$, with a well-defined sclerotic border, a communication between the joint space and the lesion, and the absence of acetabular cysts on the preoperative or early postoperative AP pelvis radiograph $[13,19]$. Of the 86 sets of radiographs evaluated, as noted earlier, 84 sets of radiographs were acceptable for wear measurements.
Two-dimensional wear analysis was performed using the method of Martell et al., a semiautomated, computerized, edge detection method [2, 4, 15, 20-22]. Each reading of linear wear (femoral head penetration) was expressed as a magnitude $(\mathrm{mm})$ and a rate $(\mathrm{mm}$ per year). Volumetric wear rate was calculated using custom equations with numerical integration based on the two-dimensional wear magnitude, femoral head size, and the direction of wear with respect to the face of the polyethylene liner [20-22]. Bedding-in (from the 6-week to 1-year postoperative radiograph) was not included in the wear measurements; rather, true wear (using the 1-year radiograph as baseline) is reported. The best method for analyzing polyethylene wear measurements is not certain or agreed on and includes the first to last, individual regression, and population regression methods [2]. For the present study, linear and volumetric wear rates were obtained using the 1-year and last followup radiographs for each hip (first to last method) [2].

Acetabular component radiographic anteversion was calculated based on the ratio of the major and minor axes of the ellipse formed by the rim of the cup ( $\sin \mathrm{a}=$ minor axis/major axis). One patient, with an anterior dislocation that was treated nonoperatively, was included in the clinical and wear analyses. The mean acetabular abduction angle was $45^{\circ}$ (range, $33^{\circ}-58^{\circ}$ ). The mean acetabular anteversion angle was $23^{\circ}$ (range, $9^{\circ}-38^{\circ}$ ). The acetabular abduction and anteversion angles among the four head size groups were not substantially different.

For the statistical analysis, we combined the hips with 36- and 40-mm femoral heads into one group classified as large. Continuous variables were tested for normality using the Anderson-Darling normality test. Acetabular abduction and anteversion angles were normally distributed. Differences in mean values for these variables between femoral head sizes were tested for significance at the $95 \%$ level $(p<0.05)$ using one-way analysis of variance. Linear and volumetric wear values did not follow a normal distribution and were tested for differences in the median values for each head classification using the Kruskal-Wallis nonparametric test for differences in medians. The relationship between the nonparametric continuous variables of linear and volumetric wear rates and any osteolysis detected (femur or pelvis) was tested at the $95 \%$ level $(\mathrm{p}<0.05)$ using univariate binary logistic regression. The effect of the categorical variable head size on the presence of lysis was tested at the $95 \%$ level using chi square analysis. Only 12 of the 72 patients had bilateral hip data; therefore, we treated all hips as statistically independent. A power analysis had previously been performed in our earlier study [15]. For this study, with the endpoint volumetric wear, given a maximum difference in medians of 23, a sample size of 84 , and a pooled SD of 23 , with 84 observations, our power is 1.00 . 


\section{Results}

For the entire cohort, the median linear wear rate was $0.024 \mathrm{~mm} /$ year (95\% confidence interval [CI], 0.0160.030; Fig. 1). For the entire cohort, the median volumetric wear rate was $12.19 \mathrm{~mm}^{3} /$ year (95\% CI, 6.6-15.7; Fig. 2).

We observed no differences with the numbers available between femoral head size and the median linear wear rate (Table 1). However, larger femoral heads were associated with more volumetric wear; $36 / 40-\mathrm{mm}$ femoral heads had higher volumetric wear (median 26.1; 95\% CI, 11.3-47.1) than did 26-mm heads (median 3.1; 95\% CI, 0.7-12.3), 28$\mathrm{mm}$ heads (median 12.3; 95\% CI, 3.0-19.3), and 32-mm heads (median 12.9; 95\% CI, 6.6-16.8; $\mathrm{p}=0.02$ ) (Table 2). Periprosthetic osteolysis was noted in 12 hips (11 patients). These lesions all were $1 \mathrm{~cm}$ or less and seen in the pelvis alone in seven hips, the proximal femur only (one calcar, one trochanter) in two hips, and in both the pelvis and proximal femur in three hips. There was no association, with the numbers available, between these small osteolytic lesions and the total volumetric

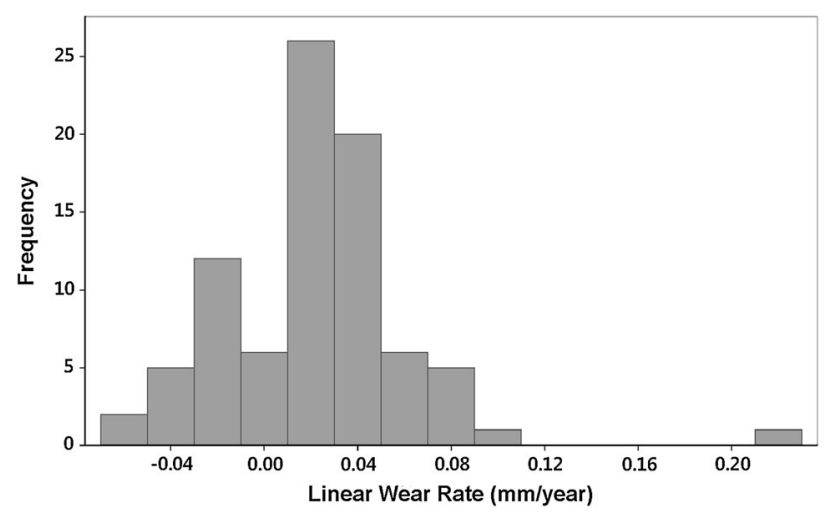

Fig. 1 This is a histogram of the linear wear rates (mm/year) for the entire cohort by the first to last method.

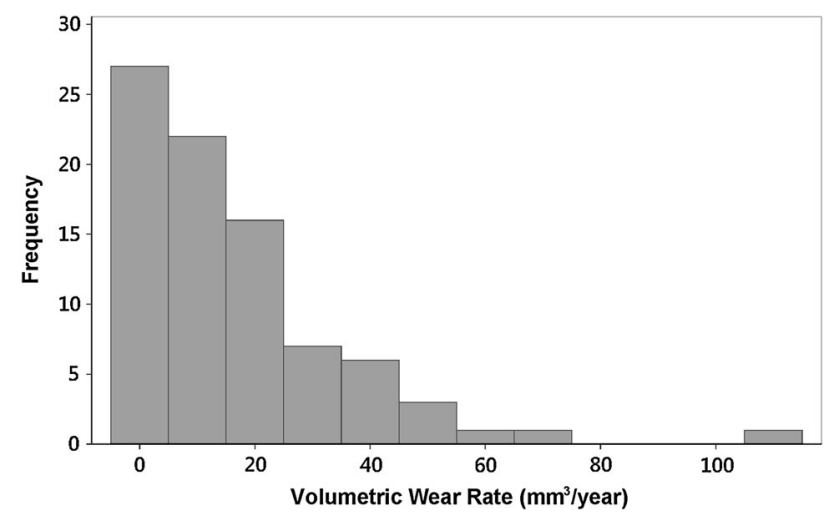

Fig. 2 This is a histogram of the volumetric wear rates $\left(\mathrm{mm}^{3} /\right.$ year $)$ for the entire cohort. polyethylene wear (with osteolysis, median $9.2 ; 95 \% \mathrm{CI}$, 1.4-19; without osteolysis, median 12.1 ; $95 \%$ CI, 7.1-16.5; $\mathrm{p}=0.224)$, the femoral head size $(26 \mathrm{~mm}$, one hip; $28 \mathrm{~mm}$, five hips; $32 \mathrm{~mm}$, three hips; $36 / 40 \mathrm{~mm}$, three hips; $\mathrm{p}=0.593$ ), femoral component fixation (with osteolysis, five of 32 cemented and seven of 52 uncemented; $\mathrm{p}=0.784$ ), or LEAS (with osteolysis, mean 9, range 7-11; without osteolysis, mean 9.7, range 6-12; $\mathrm{p}=0.09$ ). There were two patients considered "outliers," with the threshold $0.0945 \mathrm{~mm} /$ year, and one of these had osteolysis. There were no reoperations or revisions in the entire cohort.

\section{Discussion}

Periprosthetic osteolysis, resulting from polyethylene wear and particulate debris, often will lead to symptomatic component loosening or periprosthetic fracture. Highly XLPE was designed to decrease or eliminate polyethylene wear, decrease the incidence and severity of osteolysis, and hopefully increase the lifespan of THA to the 20- to 30 -year range. A number of XLPE formulations have been available for the past decade and have shown decreased wear and osteolysis at short- to medium-term followup times $[2,3,5,7,9,22]$. The senior author (PFL) has exclusively used one uncemented acetabular component with one electron beam, remelted XLPE over the past 14 years but with different femoral head sizes selected based on anatomic and demographic variables. A previous study of the midterm results showed no osteolysis but differences in volumetric wear among head sizes [15], and we wanted to determine if these results would change at longer-term followup. Thus, we asked the following questions: (1) What are the linear and volumetric wear rates of this XLPE at 10 to 14 years? (2) What is the relationship among linear wear, volumetric wear, and femoral head size? (3) What proportion of hips developed osteolysis and was there a relationship between osteolysis and femoral head size and polyethylene wear?

There are several limitations to this study. First, the study was not randomized and there were no controls with standard polyethylene. Second, the present cohort was 84 hips and there were only 12 hips with $36-$ or $40-\mathrm{mm}$ femoral heads at minimum 10-year followup. The choice of head size was not randomized, so there could have been some selection bias. However, we described our specific indications for the use of large heads. Third, of the initial cohort, there were $26 \%$ lost to followup and some of these patients might have been revised elsewhere. However, we were able to recall $82 \%$ of the earlier cohort, on which we reported the minimum 5-year followup results. Like with any long-term observational study, there is difficulty in getting patients who are asymptomatic to return for clinical 
Table 1. Linear wear rate by femoral head size

\begin{tabular}{lll}
\hline $\begin{array}{l}\text { Head } \\
\text { size }(\mathrm{mm})\end{array}$ & $\begin{array}{l}\text { Number } \\
\text { of hips }\end{array}$ & $\begin{array}{l}\text { Median linear wear rate }(\mathrm{mm} / \text { year }) \\
{[95 \% \text { confidence intervals }]}\end{array}$ \\
\hline 26 & 10 & $0.000[-0.016$ to 0.024$]$ \\
28 & 31 & $0.031[0.011-0.036]$ \\
32 & 31 & $0.021[0.012-0.028]$ \\
$36 / 40$ & 12 & $0.042[0.018-0.057]$ \\
\hline
\end{tabular}

$\mathrm{p}=0.071$

Table 2. Volumetric wear rate by femoral head size

\begin{tabular}{lll}
\hline $\begin{array}{l}\text { Head } \\
\text { size }(\mathrm{mm})\end{array}$ & $\begin{array}{l}\text { Number } \\
\text { of hips }\end{array}$ & $\begin{array}{l}\text { Median volumetric wear rate }\left(\mathrm{mm}^{3} / \text { year) }\right. \\
{[95 \% \text { confidence intervals] }}\end{array}$ \\
\hline 26 & 10 & $3.1[0.7-12.3]$ \\
28 & 31 & $12.3[3.0-19.3]$ \\
32 & $30 *$ & $12.9[6.6-16.8]$ \\
$36 / 40$ & 12 & $26.1[11.3-47.1]$ \\
\hline
\end{tabular}

* One hip excluded as a result of missing value; $\mathrm{p}=0.020$.

and radiographic evaluation. Fourth, bilateral hips were treated as independent evaluations and this might have decreased the frequency of osteolysis. However, this was only $15 \%$ of the cohort. Fifth, the use of Judet views to visualize osteolytic lesions has not been commonly used and we did not have preoperative or early postoperative Judet views of the hip so that the number of osteolytic lesions may be overestimated by false-positive arthritic cysts. However, these additional views are certainly better than just having a single AP pelvis radiograph. Sixth, there are difficulties in accurately measuring very small displacements of the femoral head into the acetabular component from plain radiographs taken over a 10-year timespan. Wear is near zero with this polyethylene implant, which makes the "noise" of the Martell measurement method more apparent [2, 15, 20-22]. Because our statistical methods deal with the range of measurements, we are able to draw conclusions on the effect of head size and volumetric wear with these data. Seventh, we only have a patient-completed validated activity scale (LEAS) at the most recent followup visit. However, based on the indications we used for these implants, there is no reason to believe that patients with high activity level were more likely to have been in the 36- and 40-mm head size group.

An additional limitation is the analysis of polyethylene wear. The best method for analyzing polyethylene wear measurements is not certain or agreed on and includes: the first to last, population regression, and individual regression methods. In this study, linear and volumetric wear rates were obtained using the first to last method [2]. In our previous study, all available wear data points were plotted as wear versus time, and the slope of the best fit line through all data points was reported as the wear rate for the population (population regression method) [15]. Additionally, in our previous study, the statistician used a new technique, linear mixed models, to adjust for multiple demographic and surgical variables in the four head size groups [15]. These statistical methods have been criticized by some investigators and its use is considered best for very large populations with multiple intermediate wear observations [2]. In the previous study, we did have multiple intermediate wear observations [15]. With the individual regression method, wear rates for each patient are calculated as the slope of the best fit line through all data points on the wear versus time plot. With the individual regression method, the linear wear rate can be a negative value, but, using the custom equations, volumetric wear cannot be a negative value. Thus, for this study, we report the results using the first to last method, because this provided the greatest precision with the least variability and because most patients were specifically recalled for the 10- to 14-year followup and did not have numerous intermediate radiographs.

There are relatively few studies of the wear of XLPE with minimum 10-year followup of XLPE, and it is difficult to compare these results with our study as a result of differences in wear measurement techniques, lack of volumetric wear, followup times, methods of component fixation, XLPE formulations, and femoral head sizes. Babovic and Trousdale [1] reported the minimum 10-year followup (mean, 10 years) of the same Longevity polyethylene in 54 hips in 50 patients who were 50 years of age or younger. Using the Roman method (head penetration measurement using free software; www.cookedbits.co.uk/ roman) [4], they reported mean femoral head penetration of $0.020 \mathrm{~mm} /$ year $(95 \% \mathrm{CI}, \pm 0.0047)$ and mean total femoral head penetration of $0.21 \mathrm{~mm}(95 \% \mathrm{CI}, \pm 0.049)$. This study was limited in that there were four manufacturers of three different femoral head sizes, the volumetric wear was not measured, and wear analysis of the three different head sizes was not performed. In addition, the Roman method of linear wear measurement has not been widely used and reported to be less accurate and precise than the Martell method [4]. Rohrl et al. [25] reported 10-year wear data of eight hips with annealed XLPE (Crossfire; Stryker, Kalamazoo, MI) cemented acetabular components using radiostereogrammetry (RSA). The mean head penetration after 10 years was $0.07 \mathrm{~mm}(95 \% \mathrm{CI}$, -0.015 to $0.153 \mathrm{~mm}$ ). However, the RSA measurements also indicated migration and rotation of the components after 7 years. Garcia-Rey et al. [11] reported the minimum 10-year results of a randomized trial of uncemented hips with 42 Durasul XLPE (Zimmer) and 41 Sulene conventional polyethylene (Zimmer) liners. All femoral heads 
were $28 \mathrm{~mm}$ but fabricated of stainless steel in the Sulene group and cobalt-chrome in the Durasul group. Wear was reported as simply femoral head penetration using "manual measurements." The mean femoral head penetration for the Durasul XLPE at 10 years was $0.31 \mathrm{~mm}$ (range, 0.11$0.92 \mathrm{~mm}$; SD $0.18 \mathrm{~mm})$. Engh et al. [9] reported the minimum 9-year (mean, 10 years) radiographic followup of a randomized trial of 79 hips with Marathon five Mrad XLPE (DePuy, Johnson \& Johnson, Warsaw, IN, USA) and 68 hips with conventional polyethylene liners, all with 28-mm femoral heads. Using the Martell method, the mean head penetration rate of the XLPE liners was $0.06 \mathrm{~mm} / \mathrm{year}$ ( $\pm 0.05 \mathrm{~mm} /$ year). However, the total linear wear and volumetric wear were not reported. There were $11 \%$ of hips with this XLPE that had linear wear rates greater than $0.10 \mathrm{~mm} /$ year, generally considered the osteolysis threshold [9]. Johanson et al. [13] reported the wear at 10-year minimum followup of 50 patients with 23 Durasul XLPE and 27 Sulene conventional cemented polyethylene components, 28-mm heads, and cemented femoral components using RSA measurements. The mean femoral head penetration between 2 and 10 years was $0.005 \mathrm{~mm} /$ year (SE, $0.002 \mathrm{~mm} /$ year) with Durasul XLPE. Again, with this RSA technique, there was measurable migration of both the acetabular and femoral components.

There are also few studies of the frequency of osteolytic lesions at minimum 10-year followup, and it is difficult to compare our study with these reports as a result of differences in type of XLPE, method of detection, and absolute length of followup. Ideally, the best methods to determine the true presence of osteolysis are CT scans [19] likely followed by comparison of preoperative and postoperative Judet views. To our knowledge, there are no studies using either technique with 10-year minimum followup. Mall et al. [19] measured the presence and volume of osteolysis on CT scans in 48 patients with Longevity XLPE liners at a minimum followup of 5 years (mean, 7 years; range, 5-11 years). This was a highly selected group, because only 48 of 240 hips with this XLPE agreed to have CT scans performed. Only one patient $(2 \%)$ of the 48 with XLPE had an osteolytic lesion seen on CT scan (volume $1.49 \mathrm{~cm}^{3}$ ). Polyethylene wear, using the Martell method comparing the 6-week and final AP pelvis radiographs, was $0.07 \mathrm{~mm} /$ year $( \pm 0.08 \mathrm{~mm} /$ year$)$. This study also evaluated osteolysis in 50 hips with standard polyethylene, and in only seven of the 13 hips with osteolysis evident on CT scan were the lesions visualized on plain AP pelvis radiographs [19]. There was no correlation between femoral head penetration (linear wear) and the presence or size of osteolytic lesions as detected by CT scan. Babovic and Trousdale [1] reported no hips with osteolysis at 10-year minimum followup, but only used the AP pelvis radiograph. In the study of Engh et al., no hip with XLPE had osteolysis at a minimum 9-year followup, but this was also based on review of the AP pelvis radiograph alone [9]. Both the studies of Rohrl et al. [25] and Garcia-Rey et al. [11] reported that no hip with XLPE had osteolysis on plain radiographs. However, Johanson et al. [13] noted focal osteolysis in the calcar region of the femur only on plain radiographs in five of 25 hips (20\%) with Durasul XLPE at 10-year followup. There were no focal osteolytic lesions in the pelvis with these cemented components. We noted osteolytic lesions in 12 hips (11 patients) comparing the first and last postoperative AP pelvis radiographs but supplemented by two Judet views of the pelvis. These lesions were all small ( $1 \mathrm{~cm}$ or less) and were detected in the periacetabular region alone in seven hips, proximal femur alone in two hips, and both the pelvis and proximal femur in three hips. These osteolytic lesions were equally divided among all four femoral head size groups and there was no association with volumetric wear rate, acetabular component abduction angle, or anteversion angle. From analyzing these studies, it is apparent that osteolysis with XLPE is related to multiple factors, including followup time, method of detection, and type of XLPE. There are also factors other than linear and volumetric wear such as each patient's response to the polyethylene particles generated that are related to the presence of osteolytic lesions in hips with XLPE.

This uncemented acetabular component with the formulation of XLPE in this study had low linear and volumetric wear rates at followup times of 10 to 14 years. There was no difference with the numbers available among the four femoral head size groups in linear wear rate. Like in our previous study, we did observe an increase in the volumetric wear rate with the larger $(36 / 40 \mathrm{~mm})$ head size compared with the other three head size groups. Additional studies from other centers are necessary before the routine use of large femoral heads with XLPE is expanded to a young and active patient population. The appearance of osteolytic lesions after 10 years is worrisome, but these were all small lesions, present with all femoral head sizes, not associated with volumetric wear rates, and the patients were asymptomatic. It is possible that we have overestimated the incidence of osteolysis with this XLPE using postoperative Judet views without similar early postoperative views. We continue to use this acetabular component with this XLPE in all patients and continue further followup of these patients. We recommend additional longer-term, likely multicenter, clinical followup studies and perhaps alternative imaging studies of patients with XLPE and osteolysis.

Acknowledgments We thank Darlene M. Urlaub for assistance in this investigation and Mr Stephen Perlman for assistance with the literature review. 


\section{References}

1. Babovic N, Trousdale RT. Total hip arthroplasty using highly cross-linked polyethylene in patients younger than 50 years with minimum 10-year follow-up. J Arthroplasty. 2013;28:815-817.

2. Bragdon CR, Doerner M, Martell J, Jarrett B, Palm H, Multicenter Study Group, Malchau H. The 2012 John Charnley Award. Clinical multicenter studies of the wear performance of highly crosslinked remelted polyethylene in THA. Clin Orthop Relat Res. 2013;471:393-402.

3. Bragdon CR, Greene ME, Freiberg AA, Harris WH, Malchau H. Radiostereometric analysis comparison of wear of highly crosslinked polyethylene against 36- vs $28-\mathrm{mm}$ femoral heads. J Arthroplasty. 2007;22(Suppl 2):125-129.

4. Crockarell JR, Snearly CM. Accuracy and precision of two computer-assisted methods of radiographic wear measurement in total hip arthroplasty. J Arthroplasty. 2012;27:37-40.

5. D'Antonio JA, Capello WN, Ramakrishnan R. Second-generation annealed highly cross-linked polyethylene exhibits low wear. Clin Orthop Relat Res. 2012;470:1696-1704.

6. DeLee JG, Charnley J. Radiological demarcation of cemented sockets in total hip replacement. Clin Orthop Relat Res. 1976;121:20-32.

7. Digas G, Karrholm J, Thanner J, Herberts P. 5-year experience of highly cross-linked polyethylene in cemented and uncemented sockets: two randomized studies using radiostereometric analysis. Acta Orthop. 2007;78:746-754.

8. Engh CA Jr, Hopper RH, Huynh C, Ho H, Sritulanondha S, Engh CA. A prospective, randomized study of cross-linked and noncross-linked polyethylene for total hip arthroplasty at 10-year follow-up. J Arthroplasty. 2012;27(Suppl 1):2-7.

9. Engh CA Jr, Stepniewski AS, Ginn SD, Beykirch SE, SychterzTerefenko CJ, Hopper RH, Engh CA. A randomized prospective evaluation of outcomes after total hip arthroplasty using crosslinked Marathon and non-cross-linked Enduron polyethylene liners. J Arthroplasty. 2006;21(Suppl 2):17-25.

10. Estok DM, Burroughs BR, Muratoglu OK, Harris WH. Comparison of hip simulator wear of two different highly cross-linked ultra high molecular weight polyethylene acetabular components using both $32-$ and $38-\mathrm{mm}$ femoral heads. J Arthroplasty. 2007;22:581-589.

11. Garcia-Rey E, Garcia-Cimbrelo E, Cruz-Pardos A. New polyethylenes in total hip replacement. A ten- to 12-year followup study. Bone Joint J. 2013;95:326-322.

12. Harris WH. Traumatic arthritis of the hip after dislocation and acetabular fracture: treatment by mold arthroplasty. An end result study using a new method of result evaluation. J Bone Joint Surg Am. 1969;51:737-755.
13. Johanson P-E, Digas G, Herberts P, Thanner J, Karrholm J. Highly crosslinked polyethylene does not reduce aseptic loosening in cemented THA 10-year findings of a randomized study. Clin Orthop Relat Res. 2012;470:3083-3093.

14. Kelley SS, Lachiewicz PF, Hickman JM, Paterno SM. Relationship of femoral head and acetabular size to the prevalence of dislocation. Clin Orthop Relat Res. 1998;355:163-170.

15. Lachiewicz PF, Heckman DS, Soileau ES, Mangla J, Martell JM. Femoral head size and wear of highly cross-linked polyethylene at 5-8 years. Clin Orthop Relat Res. 2009;467:3290-3296.

16. Lachiewicz PF, Soileau ES. Stability of total hip arthroplasty in patients 75 years or older. Clin Orthop Relat Res. 2002;405:6569.

17. Lachiewicz PF, Soileau ES. Dislocation of primary total hip arthroplasty with 36 and $40 \mathrm{~mm}$ femoral heads. Clin Orthop Relat Res. 2006;453:153-155.

18. Lachiewicz PF, Soileau ES. Second-generation modular acetabular components provide fixation at 10 to 16 years. Clin Orthop Relat Res. 2012;470:366-372.

19. Mall NA, Nunley RM, Zhu JJ, Maloney WJ, Barrack RL, Clohisy JC. The incidence of acetabular osteolysis in young patients with conventional versus highly crosslinked polyethylene. Clin Orthop Relat Res. 2011;469:372-381.

20. Martell JM, Berdia S. Determination of polyethylene wear in total hip replacements with use of digital radiographs. $J$ Bone Joint Surg Am. 1997;79:1635-1641.

21. Martell JM, Berkson E, Berger R, Jacobs J. Comparison of two and three-dimensional computerized polyethylene wear analysis after total hip arthroplasty. J Bone Joint Surg Am. 2003;85:1111-1117.

22. Martell JM, Verner JJ, Incavo SJ. Clinical performance of a highly cross-linked polyethylene at two years in total hip arthroplasty: a randomized prospective trial. J Arthroplasty. 2003;18(Suppl 1):55-59.

23. Masson P, Schmidt L, Engh CA. Evaluation of cementless acetabular component migration: an experimental study. J Arthroplasty. 1989;4:245-251.

24. Paterno SA, Lachiewicz PF, Kelley SS. The influence of patientrelated factors and the position of the acetabular component on the rate of dislocation after total hip replacement. J Bone Joint Surg Am. 1997;79:1202-1210.

25. Rohrl SM, Nivbrant B, Nilsson KG. No adverse effects of submelt-annealed highly crosslinked polyethylene in cemented cups. An RSA study of 8 patients 10 years after surgery. Acta Orthop. 2012;83:148-152.

26. Thomas GER, Simpson DJ, Mehmood S, Taylor A, McLardySmith P, Gill HS, Murray DW, Glyn-Jones S. The seven-year wear of highly cross-linked polyethylene in total hip arthroplasty. J Bone Joint Surg Am. 2011;93:716-722. 